\title{
MEMODELKAN KEMISKINAN PENDUDUK PROVINSI BALI DENGAN REGRESI DATA PANEL
}

\author{
Kadek Budinirmala $^{1 \S}$, Putu Suciptawati ${ }^{2}$, Ketut Jayanegara $^{3}$, Eka N. Kencana ${ }^{4}$ \\ ${ }^{1}$ Program Studi Matematika-Universitas Udayana [Email: budinirmala11@gmail.com] \\ ${ }^{2}$ Program Studi Matematika-Universitas Udayana [Email: suciptawati@unud.ac.id] \\ ${ }^{3}$ Program Studi Matematika-Universitas Udayana [Email: ktjayanegara@unud.ac.id] \\ ${ }^{4}$ Program Studi Matematika-Universitas Udayana [Email: i.putu.enk@unud.ac.id] \\ ${ }^{\S}$ Corresponding Author
}

\begin{abstract}
One indicator of the success of development programs undertaken is the declining percentage of the poor, defined as the ratio of the number of people classified as poor to the total population. For Bali province, despite its economic growth is higher than national rate; 6.03 percent and 6.24 percent compared to 4.88 percent and 5.02 percent in 2015 and 2016, respectively; the poor are still observed in this province by 4.15 percent of its 4.2 million population in September 2016. In order to make development programs in Bali more effective to decrease the number of poor people, significant determinants of poor have to be recognised. The purpose of this work is to model and to determine the significant factor(s) that affect the percentage of poor in Bali province by applying panel data analysis. Percentage of poor for period 2007 to 2015 is positioned as the dependent variable while economic growth, unemployment rate, labor force participation rates, total population, and human development index as the independent ones. We found the best model to describe the causal relationship among variables is fixed effect model and two predictors, the economic growth rate and human development index, were significant in affecting the number of poor in Bali province.
\end{abstract}

Keywords: Bali province, fixed effect, panel data, poverty, regression.

\section{PENDAHULUAN}

Sebagai salah satu provinsi di Indonesia, Bali tergolong provinsi yang tidak memiliki sumber daya alam dan mineral yang melimpah. Pembangunan di Provinsi Bali bertumpu kepada sektor pertanian dalam arti luas dan pariwisata yang berbasis kepada nilai-nilai budaya Bali. Bertumpu kepada kedua pilar ini, pertumbuhan ekonomi Bali pada tahun 2015 dan 2016 selalu di atas pertumbuhan ekonomi nasional, masingmasing sebesar 6.03 persen dan 6.24 persen; melebihi pertumbuhan ekonomi nasional yang tercatat sebesar 4.88 persen dan 5.02 persen pada tahun 2015 dan 2016.

Salah satu indikator keberhasilan programprogram pembangunan nasional atau regional adalah berkurangnya jumlah atau persentase dari penduduk miskin. Meskipun laju pertumbuhan ekonominya tergolong tinggi, Provinsi Bali juga tercatat sebagai salah satu provinsi yang sebagian penduduknya dikategorikan miskin. Merujuk data Survei Sosial Ekonomi Nasional (SUSENAS), jumlah penduduk miskin di Provinsi Bali pada September 2016 tercatat 174.94 ribu orang (4.15 persen), meningkat menjadi 180.13 ribu orang (4.25 persen) pada Maret 2017 (BPS Provinsi Bali, 2017), dan kembali menurun menjadi 176.48 ribu (4.14 persen) pada September 2017 (BPS, 2018).

Sebagai salah satu dari beberapa problema sosial, kemiskinan merupakan persoalan serius yang memerlukan penanganan komprehensif dengan memeriksa determinannya. Merujuk Badan Pusat Statistik (BPS) Provinsi Bali, kemiskinan dipengaruhi oleh beberapa faktor, seperti pendidikan, ketenagakerjaan, kesehatan, pertumbuhan ekonomi, dan jumlah penduduk (BPS Provinsi Bali, 2014).

Pada ilmu Statistika, data tentang penduduk miskin pada rentang waktu tertentu merupakan 
jenis data yang lazim disebut sebagai data panel. Data panel merupakan gabungan cross section dengan data time series data. Cross section data diperoleh dengan mengamati karakteristik dari sejumlah $n$ unit analisis. Karakteristik dari unit yang diamati - umumnya pada waktu yang sama - merupakan variabel yang menjadi perhatian periset. Bila variabel dari masing-masing unit analisis diamati pada $t$ waktu dengan $t>0$, maka variabel disebut variabel deret waktu. Pada data panel, unit cross section yang sama diamati selama beberapa periode waktu tertentu. Hal ini berimplikasi data panel memiliki dimensi ruang dan waktu (Gujarati, 2008).

Bila matriks data $\mathrm{D}_{\mathrm{i}}$ berukuran $t x p$ adalah matrik data panel dari $p$ variabel dan $t$ waktu untuk unit amatan ke-i $(i=1, \ldots, n)$ dan bila $p$ variabel dari setiap unit amatan $i$ bisa dibedakan menjadi $\mathbf{1}$ variabel respon $\mathbf{Y}$ dan $\mathbf{p}-\mathbf{1}$ variabel prediktor $\mathbf{X}_{\mathbf{1}}, \ldots, \mathbf{X}_{\mathbf{p}-\mathbf{1}}$; maka untuk menduga model kausal antarvariabel harus dilakukan dengan metode analisis regresi data panel. Metode regresi data panel merupakan metode regresi yang mengikutsertakan pengaruh waktu ke dalam model, dan model yang diperoleh lazim disebut sebagai model regresi data panel.

Terdapat tiga pendekatan yang dapat diaplikasikan untuk menduga model regresi data panel, yaitu: (a) common effects model (CEM) merupakan model data panel yang tersederhana mempertimbangkan model yang dibangun tidak memerhatikan perbedaan antarindividu (i) dan waktu ( $t$ ); (b) fixed effects model (FEM) adalah model yang menggunakan dummy variable untuk mengetahui perbedaan intersep antarunit amatan; dan (c) random effects model (REM) merupakan model data panel yang menyertakan variabel gangguan pada model (Greene, 2012).

Sebagai salah satu teknik analisis statistika, analisis regresi data panel umum diaplikasikan pada pemodelan data ekonomi. Ratnasari dkk (2014) menggunakan analisis regresi data panel untuk membedakan motivasi kerja karyawan yang berstatus karyawan tetap dengan berstatus tenaga outsourcing di PT. PLN cabang Gianyar. Risetnya menunjukkan FEM merupakan model terbaik dalam menjelaskan adanya perbedaan motivasi kerja menurut status karyawan, dilihat dari tiga determinan motivasi, yaitu existence, relatedness, dan growth (Sudarlan, 2015).

Suliswanto (2010) menggunakan REM untuk mengkaji pengaruh Produk Domestik Bruto (PDB) dan Indeks Pembangunan Manusia (IPM) pada kemiskinan di Indonesia. Risetnya membuktikan secara parsial PDB mampu mengurangi tingkat kemiskinan sebesar 20 persen, dan IPM sebesar 5 persen.

Data panel menggunakan CEM digunakan Apriliawan dkk. (2013) untuk menelaah determinan dari inflasi di Provinsi Jawa Tengah. Risetnya menyimpulkan Indeks Harga Konsumen, Upah Minimum Kabupaten/Kota, dan Laju Pertumbuhan Ekonomi berpengaruh nyata, dan Produk Domestik Regional Bruto (PDRB) tidak menunjukkan efek yang signifikan terhadap laju inflasi di provinsi ini.

Terkait erat dengan pentingnya programprogram pengentasan kemiskinan, penelitian ini diarahkan untuk membangun model ekonometri tentang determinan persentase penduduk miskin di 9 kabupaten/kota di Provinsi Bali. Menggunakan data sekunder yang diperoleh dari BPS, persentase penduduk miskin dari kabupaten/kota ke- $i$ pada tahun ke- $t \quad\left(Y_{i t}\right)$ dimodelkan sebagai variabel yang diduga dipengaruhi oleh 5 variabel prediktor - laju pertumbuhan ekonomi masing-masing kabupaten/kota, dinyatakan sebagai laju PDRB $\left(X_{1}\right)$, tingkat pengangguran terbuka atau TPT $\left(X_{2}\right)$, tingkat partisipasi angkatan kerja atau TPAK $\left(X_{3}\right)$, jumlah penduduk masing-masing kabupaten atau kota/POP $\left(X_{4}\right)$, dan indeks pembangunan manusia/IPM $\left(X_{5}\right)$.

\section{METODE PENELITIAN}

\subsection{Model Penelitian}

Hubungan kausal antara $Y_{i t}$ dengan kelima variabel prediktor dapat dinyatakan seperti pada persamaan (1):

$$
Y_{i t}=f\left(X_{1 i t}, X_{2 i t}, X_{3 i t}, X_{4 i t}, X_{5 i t}\right) \ldots . .
$$

dengan $i=1, \ldots, 9$; dan $t=2007, \ldots, 2015$. 


\subsection{Tahapan Analisis}

Menggunakan matriks data $D_{\text {txp }}$, dengan $t$ dan $p$ masing-masing menyatakan banyaknya tahun amatan dan jumlah variabel prediktor yang besarnya 9 dan 5, data dianalisis mengikuti tahapan berikut:

1. Mengembangkan 3 buah model regresi data panel dari persamaan (1) yaitu modelmodel CEM, FEM, dan REM. Ketiga model bisa dinyatakan dalam bentuk persamaan-persamaan berikut:

\section{a. CEM}

$Y_{i t}=\alpha+\sum_{p=1}^{5} \beta_{\mathrm{p}} X_{\mathrm{p} i t}+\mu_{i t}$

Pada (2) $\alpha, \beta$, dan $\mu_{\mathrm{it}}$ masing-masing menyatakan intercept, slope setiap variabel prediktor, dan nilai galat model.

\section{b. FEM}

Pada FEM, bisa dibentuk 2 persamaan untuk membedakan efek tetap karena beda unit amatan (fixed individual effect) dan beda waktu amatan (fixed time effect). Menurut Gudjarati (2008), saat peneliti memeriksa efek unit amatan dan unit waktu secara terpisah, maka model yang dikembangkan disebut two-way fixed effects model, sebagai alternatif dari oneway fixed effects. FEM dengan fixed individual dan fixed time effects dinyatakan sebagai (2.a) dan (2.b).

$Y_{i t}=\sum_{j=1}^{9} \alpha_{i} D_{j t}+\sum_{p=1}^{5} \beta_{\mathrm{p}} X_{\mathrm{p} i t}+\mu_{i t} \ldots \ldots$

$Y_{i t}=\sum_{s=1}^{9} \alpha_{i} D_{i s}+\sum_{p=1}^{5} \beta_{\mathrm{p}} X_{\mathrm{p} i t}+\mu_{i t}$

Pada (3.a) $D_{j t}=1$ untuk $j=i$; dan pada (3.b) $D_{i s}=1$ untuk $s=t ; 0$ selainnya.

\section{c. REM}

REM dibangun sebagai alternatif dari disertakannya variabel dummy $D$ pada (3.a) dan (3.b) dengan mengasumsikan bahwa $\alpha_{i}$ merupakan variabel acak yang bisa dinyatakan dalam bentuk $\alpha_{i}=\alpha+\varepsilon_{i}$; dengan $\varepsilon_{i} \sim F().\left(0, \sigma_{\varepsilon}^{2}\right) \quad$ (Gujarati, 2008). Melalui pendekatan ini, persamaan (2.a) dan (2.b) bisa ditulis sebagai:

$$
\begin{aligned}
& Y_{i t}=\alpha_{i}+\sum_{p=1}^{5} \beta_{\mathrm{p}} X_{\mathrm{p} i t}+w_{i t} \\
& \text { dengan } w_{i t}=\varepsilon_{i}+\mu_{i t}
\end{aligned}
$$

2. Memilih model data panel yang terbaik dari 3 model yang dibangun - CEM, FEM, dan REM. Pemilihan model dilakukan dengan Uji Chow dan Uji Hausman.

3. Memeriksa signifikansi parameter penduga dari model terpilih; dan

4. Mengintepretasikan model terpilih.

\section{HASIL PENELITIAN}

\subsection{Estimasi Model-model Data Panel}

Menggunakan $\mathrm{R}$ versi 3.2.2, tiga model data panel - CEM, FEM, dan REM - dibangun. Tabel 1, Tabel 2.a, Tabel 2.b, dan Tabel 3 memperlihatkan hasil analisis CEM, FEM dengan fixed individual effects, FEM dengan fixed time effect, dan REM.

\begin{tabular}{|c|c|c|c|c|}
\hline Variabel & Estimasi & $\begin{array}{r}\text { Nilai } \\
\text { Estimasi }\end{array}$ & $\begin{array}{r}\text { Nilai } \\
t \text { hitung }\end{array}$ & Nilai $p$ \\
\hline Intercept & $\alpha$ & 27.606 & 13.464 & 0.0000 \\
\hline Laju PDRB & $\beta_{1}$ & -1.096 & -4.436 & 0.0000 \\
\hline TPT & $\beta_{2}$ & 0.144 & 1.350 & 0.1812 \\
\hline TPAK & $\beta_{3}$ & -0.003 & -0.081 & 0.9354 \\
\hline POP & $\beta_{4}$ & 0.001 & 0.988 & 0.3264 \\
\hline IPM & $\beta_{5}$ & -0.225 & -5.030 & 0.0000 \\
\hline \multicolumn{4}{|c|}{ Nilai RSS } & 101.11 \\
\hline \multicolumn{4}{|c|}{ Nilai F-hitung } & 30.8924 \\
\hline \multicolumn{4}{|c|}{ Nilai $p$} & 0.0009 \\
\hline \multicolumn{4}{|r|}{ Nilai $\mathrm{R}^{2}$} & 0.6732 \\
\hline
\end{tabular}

Tabel 1. Estimasi Parameter pada CEM

Sumber: Hasil Analisis (2018)

Estimasi FEM dengan fixed individual dan fixed time effects dilakukan dengan teknik least square dummy variables (LSDV), dengan indeks $i=1, \ldots, 9$ pada fixed individual effects kabupaten/kota Jembrana, Tabanan, Badung, Gianyar, Klungkung, Bangli, Karangasem, Buleleng, dan Kota Denpasar; dan pada fixed time effects menyatakan tahun 2007, ..., 2015. 
Tabel 2.a. Estimasi Parameter FEM dengan Fixed Individual Effects

\begin{tabular}{lcrrr}
\hline Variabel & $\begin{array}{r}\text { Esti- } \\
\text { masi }\end{array}$ & $\begin{array}{r}\text { Nilai } \\
\text { Estimasi }\end{array}$ & $\begin{array}{r}\text { Nilai } \\
\text { hitung }\end{array}$ & Nilai $p$ \\
\hline Jembrana & $\alpha_{1}$ & 11.2775 & 1.9570 & 0.0545 \\
\hline Tabanan & $\alpha_{2}$ & 8.2825 & 1.3741 & 0.1740 \\
\hline Badung & $\alpha_{3}$ & 10.7090 & 1.8474 & 0.0691 \\
\hline Gianyar & $\alpha_{4}$ & 10.3618 & 1.8009 & 0.0762 \\
\hline Klungkung & $\alpha_{5}$ & 10.9238 & 1.9776 & 0.0521 \\
\hline Bangli & $\alpha_{6}$ & 10.2649 & 1.8999 & 0.0617 \\
\hline Karangasem & $\alpha_{7}$ & 11.3557 & 2.2669 & 0.0266 \\
\hline Buleleng & $\alpha_{8}$ & 11.8129 & 2.1245 & 0.0373 \\
\hline Denpasar & $\alpha_{9}$ & 7.2017 & 1.1342 & 0.2607 \\
\hline Laju PDRB & $\beta_{1}$ & -0.6418 & -2.5195 & 0.0141 \\
\hline TPT & $\beta_{2}$ & 0.2004 & 1.6696 & 0.0997 \\
\hline TPAK & $\beta_{3}$ & -0.0363 & -0.7400 & 0.4619 \\
\hline POP & $\beta_{4}$ & -0.0007 & -0.4278 & 0.6702 \\
\hline IPM & $\beta_{5}$ & 0.0304 & 0.4635 & 0.6445 \\
\hline \hline & & & Nilai RSS & 46.009 \\
\hline & & & Nilai F-hitung & 6.5806 \\
\hline & & & Nilai $p$ & 0.0000 \\
\hline
\end{tabular}

Sumber: Hasil Analisis (2018)

Tabel 2.b. Estimasi Parameter FEM dengan Fixed Time Effects

\begin{tabular}{lcrrr}
\hline $\begin{array}{l}\text { Variabel/ } \\
\text { Tahun }\end{array}$ & $\begin{array}{r}\text { Esti- } \\
\text { masi }\end{array}$ & $\begin{array}{r}\text { Nilai } \\
\text { Estimasi }\end{array}$ & $\begin{array}{r}\text { Nilai } \\
t \text { hitung }\end{array}$ & Nilai $p$ \\
\hline 2007 & $\alpha_{1}$ & 29.0917 & 14.9750 & 0.0000 \\
\hline 2008 & $\alpha_{2}$ & 28.1299 & 14.3860 & 0.0000 \\
\hline 2009 & $\alpha_{3}$ & 27.0618 & 13.9110 & 0.0000 \\
\hline 2010 & $\alpha_{4}$ & 27.7409 & 14.5100 & 0.0000 \\
\hline 2011 & $\alpha_{5}$ & 27.3979 & 14.0550 & 0.0000 \\
\hline 2012 & $\alpha_{6}$ & 27.1645 & 13.6790 & 0.0000 \\
\hline 2013 & $\alpha_{7}$ & 27.7418 & 13.9760 & 0.0000 \\
\hline 2014 & $\alpha_{8}$ & 28.0930 & 14.0430 & 0.0000 \\
\hline 2015 & $\alpha_{9}$ & 28.0132 & 13.9610 & 0.0000 \\
\hline Laju PDRB & $\beta_{1}$ & -0.9016 & -3.1587 & 0.0024 \\
\hline TPT & $\beta_{2}$ & 0.0624 & 0.5266 & 0.6002 \\
\hline TPAK & $\beta_{3}$ & 0.0041 & 0.1204 & 0.9045 \\
\hline POP & $\beta_{4}$ & 0.0009 & 0.9951 & 0.3233 \\
\hline IPM & $\beta_{5}$ & -0.2499 & -5.3585 & 0.0000 \\
\hline \hline & & & Nilai RSS & 76.708 \\
\hline & & Nilai F-hitung & 32.0678 \\
\hline & & Nilai $p$ & 0.0000 \\
\hline
\end{tabular}

Sumber: Hasil Analisis (2018)
Estimasi REM dilakukan dengan teknik general least square (GLS), dan memandang slope $\alpha$ merupakan variabel acak, selain komponen sisaan $\mu_{i t}$. Hasil estimasi model sebagai berikut:

Tabel 3. Estimasi Parameter pada REM

\begin{tabular}{|c|c|c|c|c|}
\hline Variabel & Estimasi & $\begin{array}{r}\text { Nilai } \\
\text { Estimasi }\end{array}$ & $\begin{array}{r}\text { Nilai } \\
t \text { hitung }\end{array}$ & Nilai $p$ \\
\hline Intercept & $\alpha$ & 18.0596 & 4.2012 & 0.0000 \\
\hline Laju PDRB & $\beta_{1}$ & -0.7258 & -2.9883 & 0.0038 \\
\hline TPT & $\beta_{2}$ & 0.1362 & 1.2620 & 0.2109 \\
\hline TPAK & $\beta_{3}$ & -0.0559 & -1.2741 & 0.2066 \\
\hline POP & $\beta_{4}$ & -0.0005 & -0.3546 & 0.7239 \\
\hline IPM & $\beta_{5}$ & -0.0473 & -0.8266 & 0.4111 \\
\hline \multicolumn{4}{|c|}{ Nilai RSS } & 87.551 \\
\hline \multicolumn{4}{|c|}{ Nilai F-hitung } & 8.3158 \\
\hline \multicolumn{4}{|c|}{ Nilai $p$} & 0.0000 \\
\hline \multicolumn{4}{|c|}{ Nilai $R^{2}$} & 0.3567 \\
\hline
\end{tabular}

Sumber: Hasil Analisis (2018)

\subsection{Pemilihan Model Terbaik}

Pemilihan model terbaik dari 3 model yang terbangun di mana FEM memiliki 2 sub-model dilakukan dengan menggunakan Uji Chow dan Uji Hausman. Uji Chow digunakan untuk memeriksa pasangan hipotesis berikut:

$\mathrm{H}_{0}$ : tidak ada perbedaan intercept pada FEM dari masing-masing kabupaten/kota

$\mathrm{H}_{1}$ : paling sedikit ada sepasang $\alpha_{i} \neq \alpha_{j}$ untuk i $\neq j$.

Pasangan hipotesis di atas diperiksa dengan statistik uji $\mathrm{F}$, yang diperoleh menggunakan persamaan (6).

$$
F_{\text {hitung }}=\frac{\left(R S S_{C E M}-R S S_{F E M}\right) /(I-1)}{R S S_{F E M} /(I T-I-P)}
$$

Pada persamaan (6), notasi I, P, dan T masingmasing menyatakan jumlah unit individu (cross sectional), jumlah prediktor, dan jumlah unit waktu (time series). Mempertimbangkan $\mathrm{H}_{0}$ menguji keberadaan fixed individual effects, maka nilai Residual Sum Squares (RSS) FEM yang digunakan adalah RSS yang diperoleh pada Tabel 2.a. Dengan demikian, diperoleh

$$
F_{\text {hitung }}=\frac{(101.11-46.009) /(9-1)}{46.009 /(81-9-5)}=10.029
$$

Memperhatikan nilai $\mathrm{F}_{\text {hitung }}>\mathrm{F}_{(0.05 ; 8,67)}=2.08$; maka $\mathrm{H}_{0}$ ditolak. Penolakan $\mathrm{H}_{0}$ menjustifikasi setidak-tidaknya terdapat 2 kabupaten/kota yang 
memiliki nilai intercept berbeda pada model data panel persentase penduduk miskin, sehingga CEM tidak layak diaplikasikan.

Untuk menentukan apakah FEM atau REM yang lebih layak digunakan setelah CEM ditolak, dilakukan Uji Hausman yang memeriksa apakah pengaruh acak $w_{i t}$ pada persamaan (5) berkorelasi ataukah tidak dengan salah satu variabel prediktor $X_{i t}$ (Gujarati, 2008). Secara formal, pasangan hipotesis pada Uji Hausman bisa dinyatakan sebagai berikut (Elhorst, 2010):

$\mathrm{H}_{0}: E\left(w_{i t} \mid X_{i t}\right)=0$

$\mathrm{H}_{1}: E\left(w_{i t} \mid X_{i t}\right) \neq 0$

Statistik yang digunakan untuk menentukan hipotesis yang akan ditolak adalah statistik $\chi^{2}$ dengan derajat bebas jumlah variabel prediktor (P) serta dihitung menggunakan persamaan (5):

$\chi_{\text {hitung }}^{2}=\widehat{\beta}^{T}(\operatorname{var}(\widehat{\beta}))^{-1} \widehat{\beta}$

dengan $\widehat{\beta}=\widehat{\beta}_{F E M}-\widehat{\beta}_{R E M}$.

Sebelum statistik $\chi^{2}$ dihitung, 1 dari 2 submodel FEM yang dibentuk dipilih. Pemilihan dilakukan dengan memperhatikan koefisien determinasi $\left(\mathrm{R}^{2}\right)$ masing-masing sub-model. Dari Tabel 2.a dan Tabel 2.b terlihat nilai $\mathrm{R}^{2}$ dari FEM dengan fixed time effects melebihi nilai $\mathrm{R}^{2}$ FEM dengan fixed time effects. Dengan demikian pada uji Hausman, $\widehat{\beta}_{F E M}$ yang dipakai adalah penduga FEM dengan fixed time effects. Nilai $\chi^{2}$ yang diperoleh menggunakan persamaan (7) adalah 20.40; lebih besar dari nilai $\chi^{2}(0.05 ; 5)$ tabel sebesar 11.07. Hasil ini menjustifikasi ada korelasi antara nilai acak pada model dengan satu atau lebih variabel prediktor $\left(\mathrm{H}_{0}\right.$ ditolak) sehingga model FEM (fixed time effects) lebih layak digunakan dibandingkan model REM.

\subsection{Pemeriksaan Signifikasi Parameter}

Model FEM yang diperoleh dengan memilih fixed time effects dengan estimasi parameter dan signifikansinya ditunjukkan pada Tabel 2.b terbukti signifikan dengan $\mathrm{F}_{\text {hitung }}=32.07>\mathrm{F}_{(0.05 ; 5,3)}$ $=9.01$. Pemeriksaan secara parsial pada slope dari setiap variabel prediktor menunjukkan Laju PDRB dan IPM merupakan 2 prediktor yang berpengaruh nyata pada persentase penduduk miskin pada masing-masing tahun amatan. Bila dicermati, koefisien penduga parameter kedua prediktor menunjukkan bila laju PDRB atau IPM meningkat di setiap tahun amatan maka jumlah persentase penduduk miskin menurun.

\section{INTERPRETASI DAN DISKUSI}

Keempat model regresi data panel yang dibentuk menunjukkan signifikansi dari model, meski nilai $\mathrm{R}^{2}$ dari masing-masing model berbeda. Berturut-turut, FEM $_{\text {fixed time }}$ CEM;

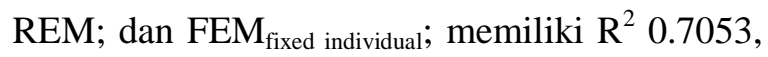
0.6732, 0.3567, dan 0.3294. Memerhatikan nilai-nilai ini maka kelima prediktor dari FEM $_{\text {fixed time }}$ dapat menjelaskan persentase penduduk miskin 70.53 persen, dan sisanya terjelaskan oleh prediktor lain yang tidak tersertakan pada model.

Pemeriksaan terhadap signifikansi penduga pada keempat model menunjukkan laju PDRB adalah satu-satunya prediktor yang memiliki pengaruh signifikan pada persentase penduduk miskin. Beberapa riset sejenis yang dilakukan di Indonesia juga mengkonfirmasi temuan tentang pengaruh laju PDRB. Menggunakan analisis jalur (path analysis), Parwata dkk (2016) menemukan PDRB Kabupaten Buleleng, Bali mampu mengurangi tingkat kemiskinan penduduk dengan pengaruh sebesar 0.473. Riset lain yang dilakukan Dama dkk. (2016) di Kota Manado, menggunakan data tahun 2005-2014, menyimpulkan berpengaruh negatif dan signifikan pada tingkat kemiskinan penduduk Kota Manado. Melalui penerapan analisis regresi linier, para peneliti memperoleh tingkat kemiskinan dapat diturunkan sebesar 0.151 bila logaritma PDRB meningkat satu satuan.

Signifikannya peran PDRB dalam menurunkan tingkat kemiskinan masyarakat tidak bisa dilepaskan dari fakta bahwasanya PDRB adalah indikator keberhasilan program pembangunan di bidang ekonomi. Peningkatan PDRB merupakan implikasi logis dari peningkatan output seluruh unit ekonomi di suatu wilayah. Selanjutnya, melalui peningkatan output maka pendapatan per kapita juga meningkat yang berpengaruh negatif pada tingkat kemiskinan penduduk.

Prediktor kedua yang memiliki koefisien (negatif) yang signifikan pada FEM $_{\text {fixed time }}$ yaitu 
IPM, yang juga signifikan pada CEM. IPM yang diukur dari 3 indikator - indeks harapan hidup, indeks pendidikan, dan indeks standar hidup layak - merupakan indikator penting untuk menilai keberhasilan program pemerintah dalam meningkatkan kualitas hidup masyarakat [1] [2]. Pada model terpilih dalam penelitian ini, model FEM $_{\text {fixed time, }}$ IPM terbukti mampu menurunkan persentase penduduk miskin di Provinsi Bali di mana meningkatnya 1 satuan nilai IPM mampu menurunkan persentase penduduk miskin 0.2499 satuan.

Bila dibandingkan dengan dengan laju PDRB, pengaruh dari IPM untuk menurunkan persentase penduduk miskin lebih rendah. Laju PDRB yang berdampak positif pada peningkatan per kapita memiliki efek 'segera' (immediate effect) pada daya beli masyarakat, sedangkan IPM lebih bersifat 'investasi' pada sumber daya manusia yang pengaruhnya pada penurunan kemiskinan terlihat setelah jangka waktu tertentu. Dengan demikian, PDRB bersifat short-term dan IPM bersifat long-term effect pada program pengentasan kemiskinan.

Pada model terpilih, FEM dengan fixed time effects, seluruh intercept menunjukkan pengaruh signifikan. Bila dicermati, $\alpha_{1}$ sebagai intercept model pada tahun 2007 memiliki nilai tertinggi yang mengindikasikan pengaruh dari prediktor lain selain lima prediktor pada model, tertinggi. Intercept terkecil ditemukan pada tahun 2012, yang menunjukkan pengaruh kelima prediktor pada model terpilih tertinggi. Mencermati nilai $\mathrm{R}^{2}$ model $=0.7053$; maka variabel prediktor lain harus ditemukan sehingga determinasi variabel prediktor meningkat.

\section{SIMPULAN DAN REKOMENDASI}

\subsection{Simpulan}

Penelitian ini menyimpulkan, dari 3 model regresi data panel yang dibangun untuk menjelaskan efek dari laju PDRB, TPT, TPAK, POP, dan IPM terhadap persentase penduduk miskin di 9 kabupaten/kota di Bali, FEM dengan fixed time effects adalah model terbaik dilihat dari nilai determinasi model sebesar 0.7053 .
Hasil analisis menjustifikasi bahwa hanya laju PDRB dan IPM yang memiliki efek nyata pada penurunan persentase penduduk miskin di Bali, dengan efek dari laju PDRB 3.6 kali lebih besar dibandingkan pengaruh IPM. Memperhatikan hal ini, diduga laju PDRB merupakan instant effect sedangkan IPM lebih mengarah kepada 'investasi' untuk menguatkan potensi masyarakat di bidang pembangunan.

\subsection{Rekomendasi}

Terkait dengan masih terbatasnya kemampuan dari kelima prediktor dalam menjelaskan perubahan persentase penduduk miskin di Bali, disarankan riset lanjutan dilakukan dengan:

1. menyertakan variabel prediktor lain yang berpotensi mempengaruhi persentase dari penduduk miskin. Sebagai misal, inflasi yang memengaruhi daya beli masyarakat; serta indeks harga konsumen layak disertakan sebagai variabel prediktor baru ke dalam model;

2. mencoba time-lag regression untuk menjustifikasi keberadaan instant vs. investation effects pada variabel prediktor dalam model data panel.

3. menguji keberadaan spatial effects pada variabel respon dan error dalam model data panel.

\section{UCAPAN TERIMAKASIH}

Penulis menyampaikan penghargaan kepada D.P.E. Nilakusmawati di Kelompok Studi Demometrika dan Komang G. Sukarsa di Grup Studi Ekonometrika Program Studi Matematika Universitas Udayana atas masukan yang berharga pada penulisan artikel ini.

\section{DAFTAR PUSTAKA}

BPS Provinsi Bali, "Bali Dalam Angka 2017," BPS Provinsi Bali, Denpasar, 2017.

BPS Indonesia, Data Sosial Ekonomi. Jakarta: Badan Pusat Statistik, 2018, vol. 98.

BPS Provinsi Bali, Profil Kemiskinan Tahun 2014. Bali: BPS Provinsi Bali, 2014. 
Damodar N Gujarati, Basics Econometrics, 5th ed. New York: The McGraw-Hill, 2008.

Dody Apriliawan, Tarno, and Hasbi Yasin, "Pemodelan Laju Inflasi di Provinsi Jawa Tengah Menggunakan Regresi Data Panel," Jurnal Gaussian, vol. 2, no. 4, pp. 301-321, 2013.

Himawan Y Dama, Agnes L Ch Lapian, and Jacline I. Sumual, "Pengaruh Produk Domestik Regional Bruto (PDRB) Terhadap Tingkat Kemiskinan di Kota Manado (Tahun 2005-2014)," Jurnal Berkala Ilmiah Efisiensi, vol. 16, no. 3, pp. 549-561, 2016.

J Paul Elhorst, "Spatial Panel Data Models," in Handbook of Applied Spatial Analysis. Berlin Heiderberg New York: Springer, 2010, p. Ch. C.2.

Made Parwata, Wayan Swendra, and Fridayana Yudiaatmaja, "Pengaruh Produk Domestik Regional Bruto (PDRB) dan Tingkat Pengangguran Terbuka Terhadap Tingkat Kemiskinan," e-Journal Bisma, vol. 4, pp. 1-10, 2016.

Ni Putu Anik M. Ratnasari, I Putu Eka N. Kencana, and G. K. Gandhiadi, "Aplikasi Regresi Data Panel dengan Pendekatan Fixed Effect Model (Studi Kasus: PT. PLN Gianyar)," e-Jurnal Matematika, vol. 3, no. 1, pp. 1-7, 2014.

S. Wahyudi Suliswanto, "Pengaruh Produk Domestik Bruto (PDB) dan Indeks Pembangunan Manusia (IPM) Terhadap Angka Kemiskinan di Indonesia," Jurnal Ekonomi Pembangunan, vol. 8, no. 2, pp. 357-366, Desember 2010.

Sudarlan, "Contribution Of Human Development Index On Per Capita Income Growth And Poverty Alleviation In Indonesia," International Journal of Science \& Scientific Technology Research, vol. 4, no. 8, pp. 173178, August 2015.

William H Greene, Econometric Analysis, 7th ed. New York: Prentice Hall, 2012. 